\title{
Predicting Aggressive Multiple Sclerosis With Intrathecal IgM Synthesis Among Patients With a Clinically Isolated Syndrome
}

Enric Monreal, MD, Susana Sainz de la Maza, MD, Lucienne Costa-Frossard, MD, Paulette Walo-Delgado, MD, Javier Zamora, PhD, José Ignacio Fernández-Velasco, MSc, Noelia Villarrubia, PhD, Mercedes Espiño, PhD, Daniel Lourido, MD, Paloma Lapuente, MD, Inmaculada Toboso, PhD, José Carlos Álvarez-Cermeño, PhD, Jaime Masjuan, PhD, and Luisa María Villar, PhD

Neurol Neuroimmunol Neuroinflamm 2021;8:e1047. doi:10.1212/NXI.0000000000001047

\section{Abstract}

\section{Objective}

To determine the best method to measure intrathecal immunoglobulin (Ig) M synthesis (ITMS), a biomarker of worse prognosis in multiple sclerosis (MS). We compared the ability for predicting a poor evolution of 4 methods assessing ITMS (IgM oligoclonal bands [OCMBs], lipid-specific OCMBs [LS-OCMBs], Reibergram, and IgM index) in patients with a clinically isolated syndrome (CIS).

\section{Methods}

Prospective study with consecutive patients performed at a referral MS center. We used unadjusted and multivariate Cox regressions for predicting a second relapse, Expanded Disability Status Scale (EDSS) scores of 4 and 6, and development of secondary progressive MS (SPMS).

\section{Results}

A total of 193 patients were included, with a median (interquartile range) age of 31 (25-38) years and a median follow-up of 12.9 years. Among all methods, only OCMB, LS-OCMB, and Reibergram significantly identified patients at risk of some of the pre-established outcomes, being LS-OCMB the technique with the strongest associations. Adjusted hazard ratio (aHR) of LS-OCMB for predicting a second relapse was 2.50 (95\% CI 1.72-3.64, $p<0.001$ ). The risk of reaching EDSS scores of 4 and 6 and SPMS was significantly higher among patients with LSOCMB (aHR 2.96, 95\% CI 1.54-5.71, $p=0.001$; aHR 4.96, 95\% CI 2.22-11.07, $p<0.001$; and aHR 2.31, 95\% CI 1.08-4.93, $p=0.03$, respectively).

\section{Conclusions}

ITMS predicts an aggressive MS at disease onset, especially when detected as LS-OCMB.

\section{Classification of Evidence}

This study provides Class II evidence that lipid-specific IgM oligoclonal bands can predict progression from CIS to MS and a worse disease course over a follow-up of at least 2 years.

\author{
Correspondence \\ Dr. Monreal \\ enricmonreal@outlook.com
}

\section{MORE ONLINE}

(III) Class of Evidence

Criteria for rating

therapeutic and diagnostic studies

NPub.org/coe 


\section{Glossary}

aHR = adjusted hazard ratio; CIS = clinically isolated syndrome; DMT = disease-modifying treatment; EDSS = Expanded Disability Status Scale; FN = false negative; FP = false positive; HRC = Hospital Universitario Ramón y Cajal; Ig = immunoglobulin; ITMS = intrathecal IgM synthesis; LS-OCMB = lipid-specific IgM oligoclonal band; MS = multiple sclerosis; $\mathbf{N P V}=$ negative predictive value; $\mathbf{O C M B}=$ IgM oligoclonal band; $\mathbf{P P V}=$ positive predictive value; $\mathbf{R R M S}=$ relapsing-remitting MS; SPMS = secondary progressive MS; TN = true negative; $\mathbf{T P}=$ true positive.

The pathogenesis of multiple sclerosis (MS) is characterized by a chronic immune activation; hence, a hallmark of the disease is intrathecal synthesis of immunoglobulins (Igs). ${ }^{1}$ In this regard, different methods have been described to assess the intrathecal humoral immune response: quantitative (CSF/serum quotients diagrams with or without hyperbolic reference range, such as the Reibergram and Ig index) ${ }^{2-4}$ and qualitative (detection of oligoclonal bands [OCBs]). ${ }^{1,5}$

Most of the Igs found in the CSF of patients with MS consist of the IgG isotype that is present in $>95 \%$ of cases ${ }^{5}$ and thus contribute to the diagnosis of the disease. ${ }^{6}$ In contrast, intrathecal synthesis of IgM (ITMS) is present in a lower proportion of patients with MS $(28 \%-55 \%),{ }^{7,8}$ and its role is mainly prognostic. As the course of MS is highly variable, ${ }^{9}$ an urgent need for reliable biomarkers at the initial stage of the disease exists for accurately predicting those patients at a higher risk of a more severe evolution. ITMS has been generally related to worse outcomes throughout the disease, ${ }^{10-28}$ although negative results have also been described. ${ }^{29-31}$ However, reliable results can be obtained with both quantitative (IgM index and Reibergram) $)^{4,5}$ and qualitative (IgM OCB [OCMB], including analysis for specificity to lipidslipid-specific OCMB [LS-OCMB] $)^{5,32,33}$ methods. Although previous data encourage the use of qualitative over quantitative analyses, ${ }^{34}$ extensive discussion arose over the predictive value of each technique. ${ }^{13,35,36}$

The aim of this study was to compare 4 methods evaluating ITMS (OCMB, LS-OCMB, Reibergram, and IgM index) among patients with a clinically isolated syndrome (CIS) with respect to the capability of these methods to predict a second relapse, Expanded Disability Status Scale (EDSS) scores of 4 and 6, and development of secondary progressive MS (SPMS).

\section{Methods}

\section{Study Design}

A single-center, observational study with prospective collection of data was performed at the Hospital Universitario Ramón y Cajal (HRC) referral MS center, Madrid. Consecutive patients with a first typical demyelinating attack suggestive of MS (CIS), with an available MRI study at baseline and a CSF analysis were initially included. The eligibility criteria included several parameters: (1) absence of previous history of possible demyelinating events, (2) follow-up of at least 2 years, (3) CSF analysis, including intrathecal IgG and
IgM synthesis, and (4) absence of a final diagnosis different from MS.

\section{Standard Protocol Approvals, Registrations, and Patient Consents}

The study was approved by the institutional ethics board of HRC. A signed informed consent was obtained from all patients.

\section{Data Collection}

Patients attending our MS Unit starting in June 1996 who agreed to participate were prospectively collected after providing signed informed consent. Participants fulfilling the inclusion criteria were recruited until December 2017, and the follow-up period was until July 05, 2020. Variables collected included demographic, clinical, radiologic, and CSF data. Details of disease-modifying treatments (DMTs) that were administered during disease evolution with dates of onset and discontinuation were also recorded. DMTs were classified into 2 groups for analytical purposes: (1) all interferon- $B$ formulations, glatiramer acetate, teriflunomide, dimethyl fumarate, fingolimod, azathioprine, and methotrexate and (2) natalizumab, alemtuzumab, ocrelizumab, rituximab, mitoxantrone, and cyclophosphamide. Only treatments maintained for a period of $\geq 3$ months were considered.

The end points that were assessed in the present study consisted of 3 parameters: (1) development of a second relapse, (2) reaching an irreversible 6-month confirmed EDSS score of 4 or 6, and (3) conversion to SPMS.

\section{Clinical Definitions}

A relapse was defined as a single clinical episode of patientreported symptoms with objective findings reflecting a demyelinating event involving the CNS with a duration of at least 24 hours (in the absence of fever or infection). ${ }^{37}$ The diagnosis of MS was established according to 2017 McDonald criteria. ${ }^{6}$ Scores of 4 and 6 based on the EDSS were only considered if they were irreversible and 6-month confirmed. Finally, we used the recent criteria proposed for the diagnosis of SPMS. ${ }^{38}$

\section{Procedures}

MRI scans were performed on a 0.5 or 1.5 -T magnet with a slice thickness varying from 2 to $5 \mathrm{~mm}$. Images were obtained in the axial plane, using the following pulse sequences: T1weighted conventional spin-echo, spin-echo proton-density weighted, T2-weighted spin-echo, and/or fluid-attenuated inversion recovery sequence. Lumbar punctures were performed 


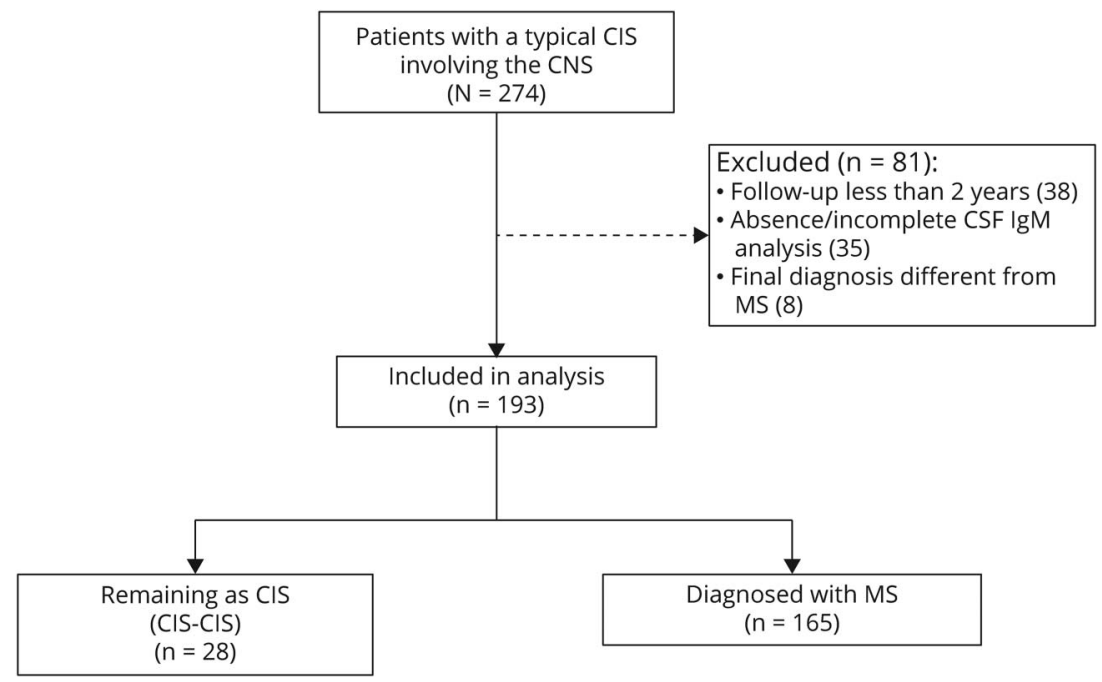

$\mathrm{CIS}=$ clinically isolated syndrome; $\mathrm{Ig}=$ immunoglobulin; MS = multiple sclerosis.

by trained neurologists in nontreated patients or in those at least 3 months after the last corticosteroid dose.

\section{CSF Analysis}

Intrathecal IgM synthesis was calculated using 2 quantitative and 2 qualitative methods within a month after sample collection. Samples were stored at $-80^{\circ} \mathrm{C}$ until assayed. Serum and CFS IgG, IgM, and albumin were quantified by nephelometry using a BN ProSpec nephelometer (Siemens Healthcare Diagnostics, Marburg, Germany). A plot of CSF/ serum quotients with hyperbolic function provided the IgM Reibergram. A Reibergram ${ }^{4}>0 \%$ and an IgM index value $>0.1$ as previously reported ${ }^{14,28,34}$ were considered hereinafter as increased. OCMB and LS-OCMB were studied in serum and CSF via isoelectric focusing and immunoblotting as previously described. ${ }^{13} \mathrm{~A}$ patient was considered to have OCMB when $\geq 2 \operatorname{IgM}$ bands were detected in the CSF but not in the paired serum sample. Whenever OCMB additionally recognized CNS lipids, LS-OCMB was reported as positive.

\section{Classification of Evidence}

Our primary research question was to compare the prognostic value of 4 methods assessing ITMS to predict the risk of a second relapse and a worse disease course in patients with a CIS. The classification of evidence assigned to this question is Class II.

\section{Statistical Analysis}

Continuous variables were reported as mean $\pm \mathrm{SD}$ or median with range or interquartile range (IQR) and were evaluated with the Wilcoxon rank-sum test. Categorical variables were described using absolute and relative frequencies and analyzed with a $\chi^{2}$ or Fisher exact test when appropriate. The kappa statistic was used for the between-methods agreement analysis.
We performed Cox proportional hazard regressions to estimate the adjusted hazard ratios (aHRs) along with 95\% $\mathrm{CI}$ as measures of association between test results and end points. Adjustments were made for potential confounding factors (sex, age at CIS, topography of CIS, disease duration at the time of lumbar puncture, and treatments received $>3$ months before outcome assessment). Time to second relapse and disability end points (EDSS scores 4 and 6 and SPMS development) were compared using Kaplan-Meier curves and a log-rank test. Patients who did not reach SPMS or with final EDSS scores of $<4$ during follow-up were considered as censored at the time of last clinical assessment.

The following indices were calculated along with corresponding 95\% CI for all end points:

- Sensitivity: $(\mathrm{TP} /[\mathrm{TP}+\mathrm{FN}]) \times 100$

- Specificity: $(\mathrm{TN} /[\mathrm{TN}+\mathrm{FP}]) \times 100$

- Positive predictive value $(\mathrm{PPV}):(\mathrm{TP} /[\mathrm{TP}+\mathrm{FP}]) \times 100$

- Negative predictive value $(\mathrm{NPV}):(\mathrm{TN} /[\mathrm{TN}+\mathrm{FN}]) \times$ 100

True positives (TPs) were considered those test positive cases (with ITMS) reaching the end point of interest (conversion to relapsing-remitting MS [RRMS]/SPMS or reaching EDSS scores of 4 or 6) during follow-up, and false positives (FPs) were considered those test positive cases that did not. Patients with a negative test result (without ITMS) but presenting with the end points were considered false negatives (FNs), whereas those remaining as CIS or with EDSS scores $<4$ during follow-up were considered as true negatives (TNs). For the between-methods comparisons of sensitivity and specificity, we applied the McNemar test. 
Table 1 Patient Characteristics

\begin{tabular}{|c|c|}
\hline & $\begin{array}{l}\text { Patients with CIS } \\
(n=193)\end{array}$ \\
\hline Age, y, median (IQR) & $31(25-38)$ \\
\hline Women, n (\%) & $130(67.4)$ \\
\hline \multicolumn{2}{|l|}{ CIS type } \\
\hline Optic nerve & $47(24)$ \\
\hline Brainstem & $51(26)$ \\
\hline Spinal cord & $73(37.2)$ \\
\hline Cerebral hemisphere & $16(8.2)$ \\
\hline Multifocal & $5(2.6)$ \\
\hline Paroxysmal symptoms & $4(2)$ \\
\hline Time of follow-up, y, median (IQR) & $12.9(6.1-18.2)$ \\
\hline $\begin{array}{l}\text { EDSS score at first relapse, } \\
\text { median (range) }\end{array}$ & $2(1-6)$ \\
\hline $\begin{array}{l}\text { Baseline EDSS score after the first relapse, } \\
\text { median (range) }\end{array}$ & $1(0-3,5)$ \\
\hline \multicolumn{2}{|l|}{ T2 lesions at baseline, $n(\%)$} \\
\hline 0 & $12(6.4)$ \\
\hline $1-3$ & $34(18.1)$ \\
\hline 4-9 & $48(25.5)$ \\
\hline $10-50$ & $80(42.6)$ \\
\hline$>50$ & $14(7.5)$ \\
\hline Gadolinium-enhancing lesions, median (range) & $0(0-15)$ \\
\hline Time to lumbar puncture, mo, median (IQR) & $5.38(1.08-21.1)$ \\
\hline CSF IgG OCB, n (\%) & $156(80.8)$ \\
\hline CSF IgG index, median (IQR) & $0.8(0.60-1.07)$ \\
\hline \multicolumn{2}{|l|}{ DMT at the time of CIS, $n(\%)$} \\
\hline First line $\mathrm{e}^{\mathrm{a}}$ & $30(15.5)$ \\
\hline Second line ${ }^{b}$ & $3(1.6)$ \\
\hline Time to first treatment, y, median (IQR) & $2.07(0.90-4.72)$ \\
\hline \multicolumn{2}{|c|}{$\begin{array}{l}\text { Abbreviations: CIS = clinically isolated syndrome; DMT = disease-modify- } \\
\text { ing treatment; EDSS = Expanded Disability Status Scale; Ig = immuno- } \\
\text { globulin; IQR = interquartile range; OCB = oligoclonal band. } \\
\text { a First line: subcutaneous or IM interferon- } \beta \text {, glatiramer acetate, teri- } \\
\text { flunomide, dimethyl fumarate, fingolimod, azathioprine, and methotrexate. } \\
\text { b Second line: natalizumab, alemtuzumab, ocrelizumab, rituximab, mitox- } \\
\text { antrone, and cyclophosphamide. }\end{array}$} \\
\hline
\end{tabular}

All analyses were conducted using Stata 14 (StataCorp, College Station, TX). All tests were 2 tailed, with $p<0.05$ as the level of statistical significance.

\section{Data Availability}

The data sets generated during and/or analyzed during the current study are available from the corresponding author on reasonable request.

\section{Results}

\section{Patient Characteristics}

Two hundred seventy-four patients with a typical CIS involving the CNS were initially included. We excluded participants with a follow-up of $<2$ years $(n=38)$, with absence or incomplete CSF IgM analysis $(n=35)$, and with a final diagnosis different from MS $(n=8)$ as shown in Figure 1, representing a $29.6 \%$ of dropouts. A total of 193 patients were included in the analyses, 130 (67.4\%) women with a median (IQR) age at CIS of $31(25-38)$ years. Patients were followed up for a median (IQR) of 12.9 (6.1-18.2) years. Table 1 outlines the baseline characteristics of all patients. During the course of their disease, most patients received at least $1 \mathrm{DMT}$ (eTable 1, links.lww.com/ NXI/A514).

\section{Intrathecal IgM Synthesis}

Seventy-two (37.3\%) patients had $\geq 2$ OCMBs and were considered positive, whereas $53(27.5 \%)$ had also LSOCMBs and 32 (16.6\%) showed a positive Reibergram. An index $>0.1$ was observed in 81 (42\%) patients. The between-methods agreement analysis using the kappa statistic is shown in eTable 2 (links.lww.com/NXI/A514). As expected, agreement was highest between OCMB and LS-OCMB (substantial agreement, $\kappa=0.77$ ), followed by IgM index and Reibergram, which was moderate ( $\kappa$ $=0.41)$.

\section{Second Relapse}

One hundred forty-nine (77.2\%) patients experienced a second relapse during follow-up. Overall, the risk was $40.4 \%, 53.9 \%$, and $72.4 \%$ after 12,24 , and 60 months, respectively. Neither Reibergram nor IgM index $>0.1$ identified patients experiencing a subsequent relapse. Conversely, both OCMB and LS-OCMB were significantly associated with a higher risk of a second relapse at a shorter time (aHR 2.11, 95\% CI 1.51-2.96, $p<0.001$; and aHR 2.50, 95\% CI 1.72-3.64, $p<0.001$, respectively) (Table 2). After 12 months, the risk was $66 \%$ among patients with LSOCMB compared with $30.7 \%$ among patients without LSOCMB, increasing to $83.7 \%$ and $68.1 \%$, respectively, after 5 years, as shown in Figure 2. The Kaplan-Meier curves of all methods are shown in Figure 2.

\section{Disability End Points}

Forty-one patients (21.2\%) reached an EDSS score of 4. After 10 and 15 years, the Kaplan-Meier estimate of cumulative incidence was $14.2 \%$ and $24.8 \%$, respectively. The risk of the EDSS score of 4 after 10 and 15 years was $26.3 \%$ and $40.7 \%$, respectively, among patients with LS-OCMB compared with $9 \%$ and $18 \%$, respectively, among patients without LS-OCMB (aHR 2.96, 95\% CI 1.54-5.71; $p=$ 0.001). Both Reibergram and OCMB showed a trend toward a higher risk of reaching an EDSS score of 4 (aHR 2.02, 95\% CI 0.96-4.23, $p=0.064$, and aHR 1.75, 95\% CI $0.94-3.28, p=0.08$, respectively) (Table 2). Conversely, 
Table 2 Unadjusted and Multivariable Cox Regression Models for Predicting the Risk of a Second Relapse, Reaching EDSS Scores of 4 and 6, and Development of SPMS

\begin{tabular}{|c|c|c|c|c|c|c|}
\hline & \multicolumn{3}{|c|}{ Unadjusted } & \multicolumn{3}{|c|}{ Multivariable model $^{a}$} \\
\hline & $H R$ & $95 \% \mathrm{Cl}$ & $p$ Value & HR & $95 \% \mathrm{Cl}$ & $p$ Value \\
\hline \multicolumn{7}{|l|}{ Second relapse } \\
\hline ОСМВ & 1.75 & $1.26-2.43$ & 0.001 & 2.11 & $1.51-2.96$ & $<0.001$ \\
\hline LS-OCMB & 1.99 & $1.40-2.84$ & $<0.001$ & 2.50 & $1.72-3.64$ & $<0.001$ \\
\hline Reibergram & 0.69 & $0.43-1.10$ & 0.12 & 0.70 & $0.43-1.13$ & 0.14 \\
\hline IgM index (>0.1) & 0.96 & $0.69-1.34$ & 0.82 & 0.99 & $0.71-1.38$ & 0.94 \\
\hline \multicolumn{7}{|l|}{ EDSS score 4} \\
\hline OCMB & 1.94 & $1.05-3.58$ & 0.035 & 1.75 & $0.94-3.28$ & 0.08 \\
\hline LS-OCMB & 2.83 & $1.53-5.23$ & 0.001 & 2.96 & $1.54-5.71$ & 0.001 \\
\hline Reibergram & 2.10 & $1.02-4.29$ & 0.043 & 2.02 & $0.96-4.23$ & 0.06 \\
\hline IgM index $(>0.1)$ & 1.58 & $0.85-2.94$ & 0.15 & 1.45 & $0.77-2.73$ & 0.25 \\
\hline \multicolumn{7}{|l|}{ EDSS score 6} \\
\hline OCMB & 2.44 & $1.16-5.12$ & 0.018 & 2.42 & $1.12-5.20$ & 0.02 \\
\hline LS-OCMB & 3.95 & $1.88-8.28$ & $<0.001$ & 4.96 & $2.22-11.07$ & $<0.001$ \\
\hline Reibergram & 2.15 & $0.91-5.06$ & 0.08 & 2.29 & $0.95-5.52$ & 0.065 \\
\hline IgM index $(>0.1)$ & 1.67 & $0.80-3.49$ & 0.17 & 1.56 & $0.73-3.33$ & 0.25 \\
\hline \multicolumn{7}{|l|}{ SPMS } \\
\hline ОСМВ & 1.81 & $0.90-3.64$ & 0.09 & 1.52 & $0.74-3.15$ & 0.26 \\
\hline LS-OCMB & 2.45 & $1.22-4.91$ & 0.01 & 2.31 & $1.09-4.93$ & 0.03 \\
\hline Reibergram & 2.39 & $1.06-5.36$ & 0.035 & 2.33 & $1.01-5.36$ & 0.048 \\
\hline IgM index $(>0.1)$ & 1.43 & $0.71-2.91$ & 0.32 & 1.28 & $0.61-2.68$ & 0.51 \\
\hline
\end{tabular}

Abbreviations: $\mathrm{CIS}=$ clinically isolated syndrome; EDSS = Expanded Disability Status Scale; HR = hazard ratio; Ig = immunoglobulin; IF = intrathecal fraction; LS$\mathrm{OCMB}=$ lipid-specific IgM oligoclonal band; OCMB = IgM oligoclonal band; SPMS = secondary progressive multiple sclerosis.

${ }^{a}$ Cox proportional hazard regression, adjusted by sex, age at CIS, topography of CIS, disease duration at the time of lumbar puncture, and disease-modifying treatments as time-dependent covariates.

Italics indicate differences are statistically significant $(p<0.05)$.

IgM index $>0.1$ was not associated with a higher risk of this outcome. The cumulative incidence of disability end point curves according to LS-OCMB and Reibergram results are detailed in Figure 3, whereas the Kaplan-Meier curves of $\mathrm{OCMB}$ and IgM index are shown in Figure 4.

The need for an assisted device to walk, that is an EDSS score of 6 , was observed in $15 \%$ of patients $(8.9 \%, 18.1 \%$, and $25.9 \%$ after 10,15 , and 20 years, respectively). LS-OCMB showed the most accurate prediction of the risk of an EDSS score of 6 (aHR 4.96, 95\% CI 2.22-11.07; $p<0.001$ ) (Table 2), as $17.9 \%, 36.2 \%$, and $49.8 \%$ of patients with LS-OCMB reached this end point after 10,15 , and 20 years, respectively. In contrast, only $5.1 \%, 10 \%$, and $14.9 \%$ of patients without LSOCMB showed progression to EDSS of 6 after the same periods, respectively. The presence of OCMB, even without a lipid specificity, was also associated with a significant higher risk, but this method provided a lower prediction (aHR 2.42,
95\% CI 1.13-5.20; $p=0.02$ ). On the other side, Reibergram and index were related to a not significant higher risk $(p=$ 0.065 and $p=0.25$, respectively) (Table 2, Figures 3 and 4).

The development of SPMS was observed in $17.3 \%$ and $30.9 \%$ of patients after 15 and 20 years, respectively. The cumulative incidence was significantly different between those patients with LS-OCMB and those without $(24.6 \%$ and $51 \%$ vs $14.2 \%$ and $20.4 \%$ after 15 and 20 years, respectively) (aHR 2.31, 95\% CI 1.08-4.93; $p=0.03$ ). The Reibergram also predicted the conversion to SPMS (aHR 2.33, 95\% CI 1.01-5.36; $p=$ 0.048 ), unlike OCMB and IgM index (Table 2, Figures 3 and 4).

We further performed analyses of sensitivity and specificity for all methods to test their accuracy for predicting disability outcomes. As shown in eFigure 1 (links.lww.com/NXI/ A514), LS-OCMB showed the highest performance with a 
A. OCMB

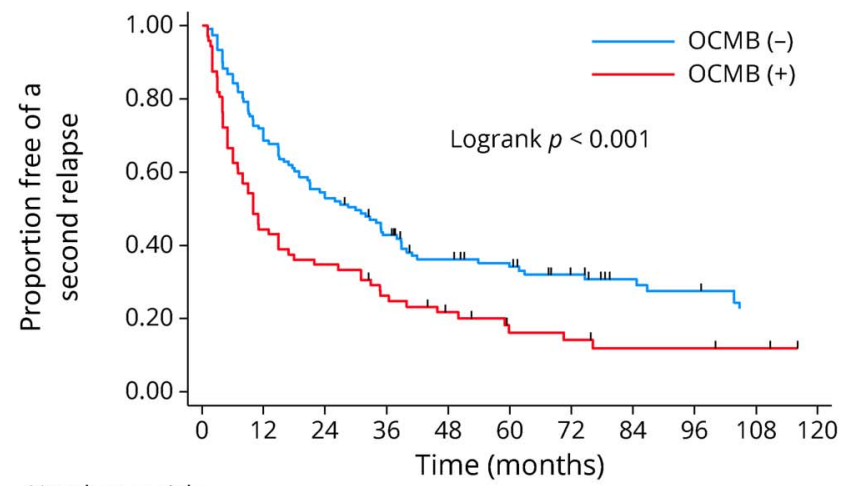

Number at risk:

$\begin{array}{ccccccccccc}121 & 84 & 64 & 50 & 38 & 33 & 26 & 20 & 18 & 14 & 14 \\ 72 & 32 & 25 & 18 & 13 & 8 & 7 & 5 & 5 & 4 & 2\end{array}$

C. Reibergram

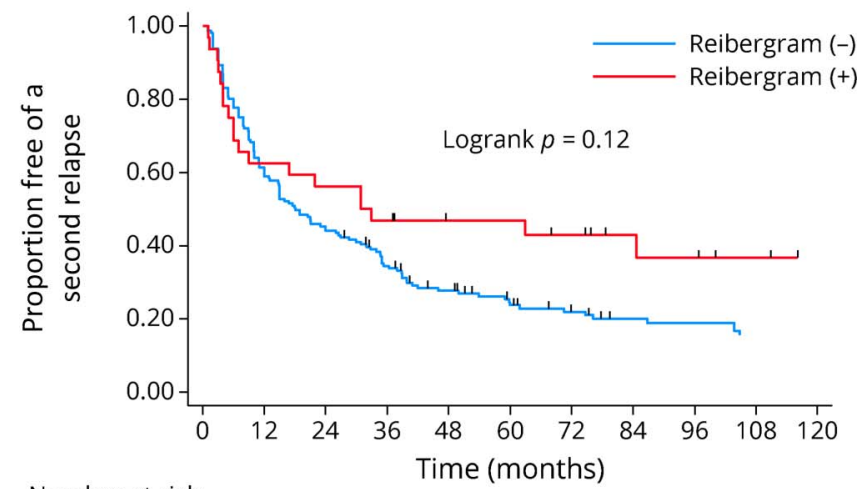

Number at risk:

$\begin{array}{ccccccccccc}161 & 96 & 71 & 53 & 39 & 29 & 23 & 18 & 17 & 14 & 14 \\ 32 & 20 & 18 & 15 & 12 & 12 & 10 & 7 & 6 & 4 & 2\end{array}$

B. LS-OCMB

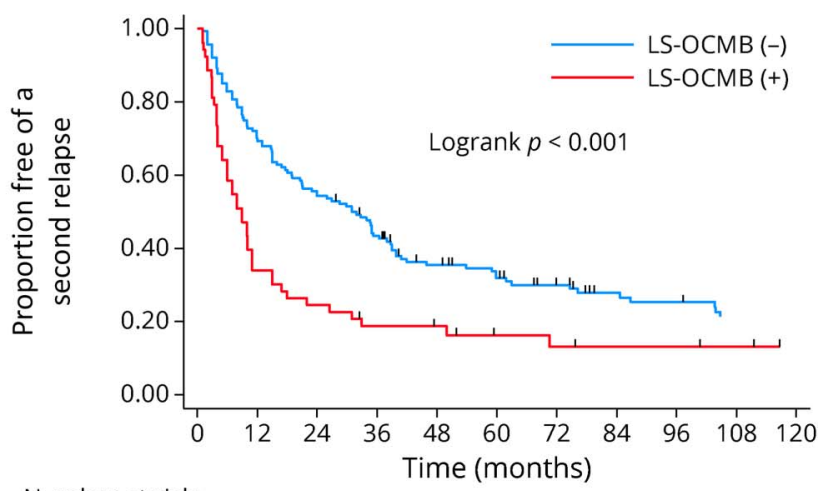

Number at risk:

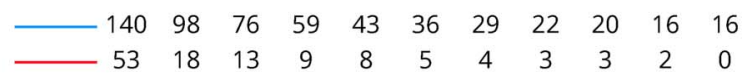

D. IgM index

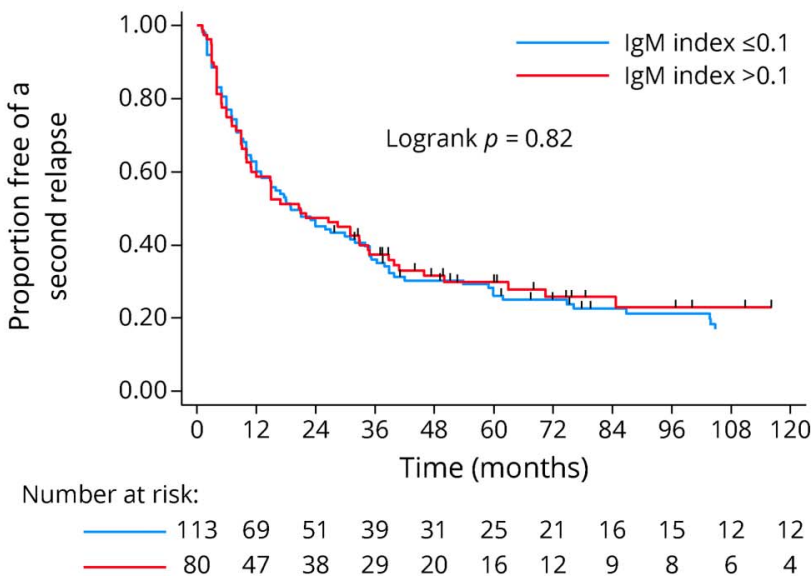

Kaplan-Meier survival curves and results from the log-rank test for the survival-free probability of a second relapse with (A) OCMB, (B) LS-OCMB, (C) Reibergram, and (D) IgM index. Ig = immunoglobulin; ITMS = intrathecal IgM synthesis; OCMB = IgM oligoclonal band; LS-OCMB = lipid-specific IgM oligoclonal band.

moderate sensitivity and a high specificity. Although Reibergram slightly improved specificity, differences were not significant except for SPMS $(p=0.035)$. Conversely, LS-OCMB provided a 2-fold higher sensitivity for reaching EDSS scores of 4 and 6 and SPMS ( $p<0.01$ for all comparisons) (eFigure 1). Neither OCMB nor IgM index improved sensitivity compared with LS-OCMB, and specificity was significantly lower $(p<0.001)$. The PPV and NPV of all methods are shown in eTable 3.

\section{Sensitivity Analyses}

To evaluate the robustness of the results, we performed the following sensitivity analysis restricting the analysis to several groups of patients: (1) patients with clinically definite MS (n = 149) (eTable 4, links.lww.com/NXI/A514), (2) patients with a $2017 \mathrm{McDonald}$ RRMS ( $\mathrm{n}=165)$ (eTable 5), and (3) patients with at least 10 years of follow-up $(n=120)$ (eTable 6 ). All analyses yielded similar results as seen with the main one.

\section{Discussion}

The recognition and validation of reliable and reproducible biomarkers to predict the evolution of patients with MS is a main field of investigation. The monoclonal antibodies approved for use in treating MS provided considerable improvements in terms of efficacy ${ }^{39,40}$ and improved the prognosis of patients, especially when initiated at an early stage. $^{41-44}$ However, serious or life-changing adverse events are more frequent with these DMTs, and thus, treatment decisions have gained complexity because benefits must be thoroughly balanced with risks. ${ }^{45}$ The availability of a test accurately recognizing patients at high risk of disability at disease onset and therefore who are candidates for these highly effective DMTs may tip the balance in favor of prescribing them at an early stage. In most cases, CSF analysis will be performed only once, but CSF parameters that remain steady throughout the disease with a prognostic value might be of a great value. The intrathecal 
Figure 3 Time to EDSS Scores of 4 and 6 and Conversion to Secondary Progressive Multiple Sclerosis With LS-OCMB and Reibergram

A

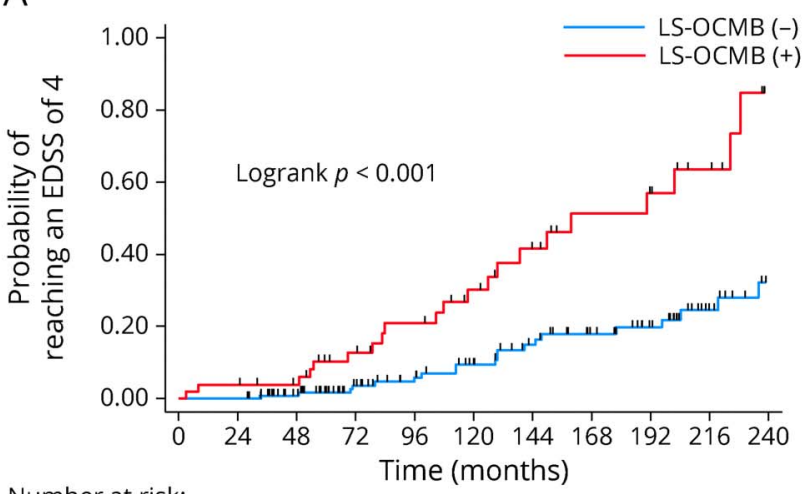

Number at risk:

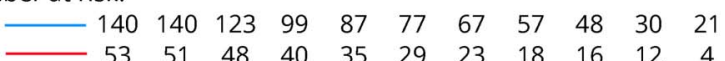

C

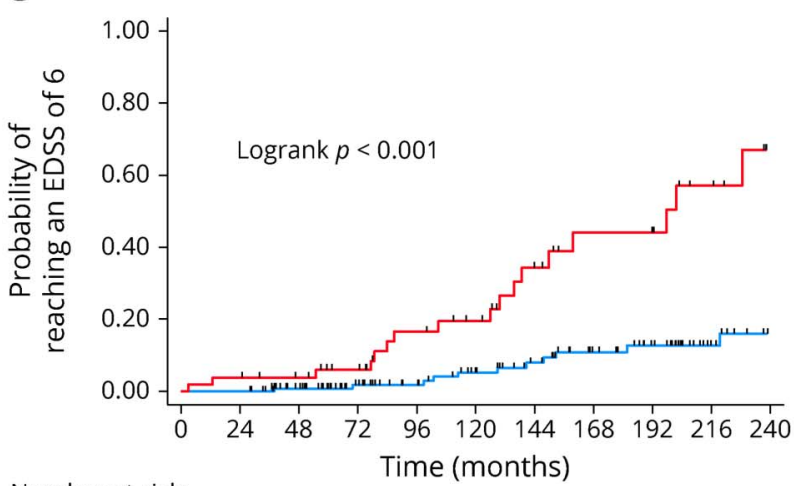

Number at risk:

$\left[\begin{array}{lllllllllll}140 & 140 & 123 & 101 & 90 & 79 & 70 & 58 & 49 & 31 & 23\end{array}\right.$

$\mathrm{E}$

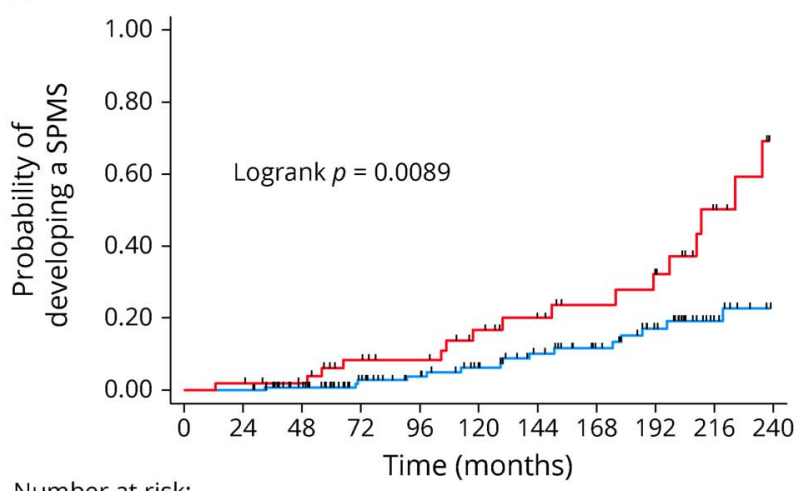

Number at risk:

$$
\begin{array}{ccccccccccc}
140 & 140 & 123 & 100 & 89 & 79 & 69 & 59 & 48 & 30 & 22 \\
-53 & 52 & 49 & 42 & 39 & 33 & 28 & 24 & 21 & 13 & 5
\end{array}
$$

B Reibergram

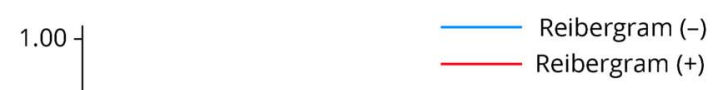

Number at risk:

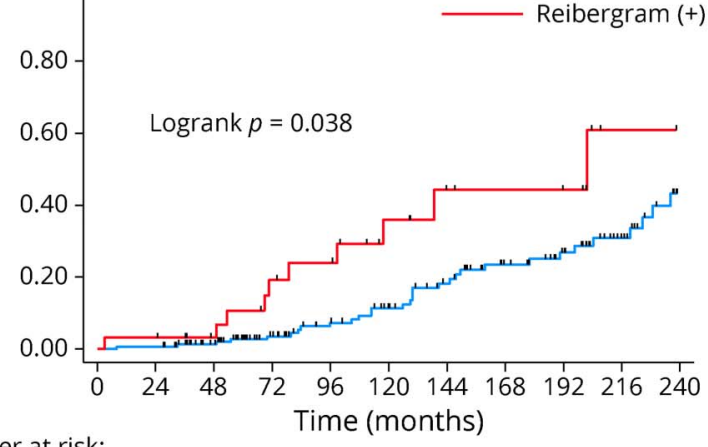

$\begin{array}{llllllllllll}161 & 160 & 144 & 117 & 102 & 92 & 80 & 66 & 56 & 39 & 24\end{array}$

$\mathrm{D}$

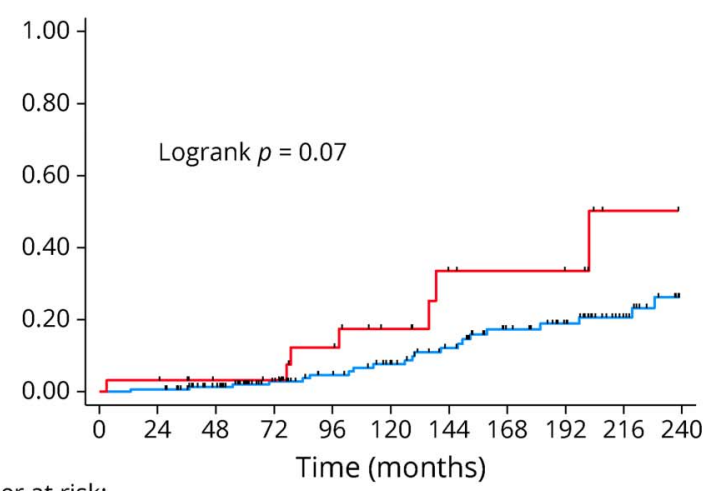

Number at risk:

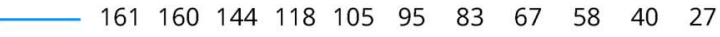

$\mathrm{F}$

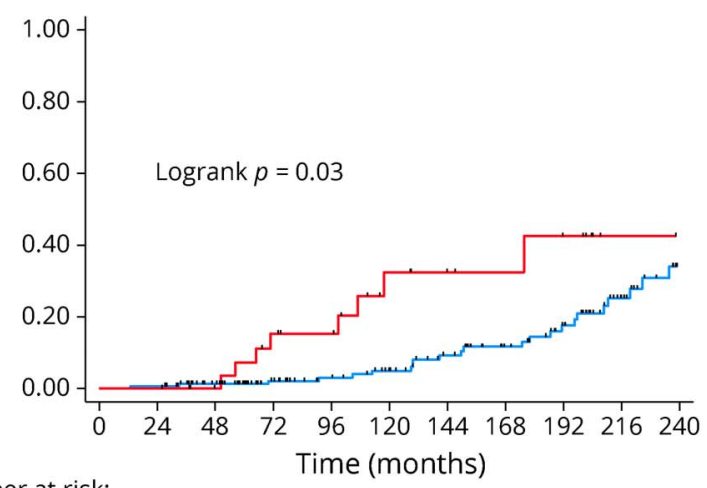

Number at risk:

$\begin{array}{llllllllllll}161 & 160 & 144 & 119 & 107 & 98 & 86 & 73 & 61 & 40 & 26\end{array}$

Cumulative incidence and results from the log-rank test for (A, B) EDSS score 4, (C, D) EDSS score 6, and (E, F) development of SPMS with (A, C, E) LS-OCMB and $(B, D, F)$ Reibergram. EDSS = Expanded Disability Status Scale; Ig = immunoglobulin; LS-OCMB = lipid-specific IgM oligoclonal band; SPMS = secondary progressive multiple sclerosis.

synthesis of IgM has been proposed as a prognostic factor for nearly 30 years, but methodological problems have been proposed $^{35,46}$ against a general incorporation of routine CSF analysis. IgM is present in CSF at a clearly lower concentration than IgG and has a higher molecular weight due to its pentameric structure. Thus, a proper storage is crucial to measure accurately ITMS. In this context, we performed this study following a large cohort of patients 
Figure 4 Time to EDSS Scores of 4 and 6 and Conversion to Secondary Progressive Multiple Sclerosis With OCMB and IgM Index

A

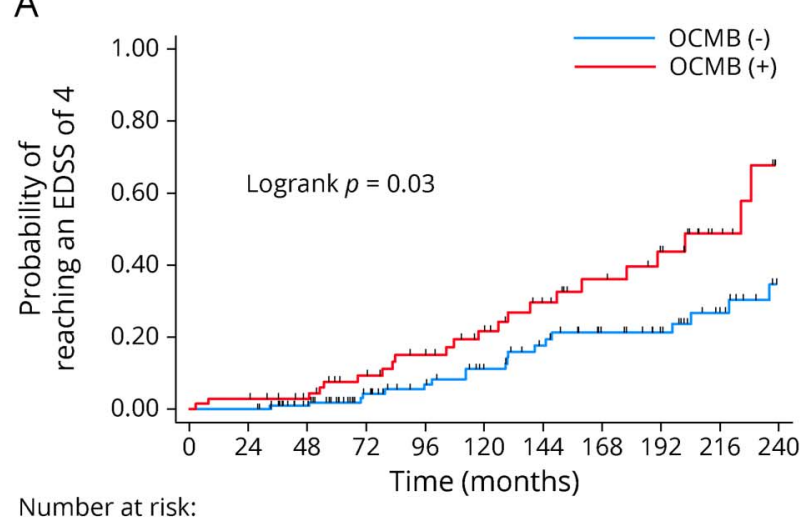

Number at risk:

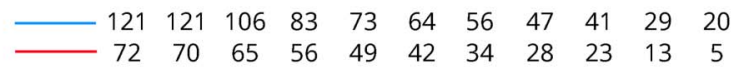

C

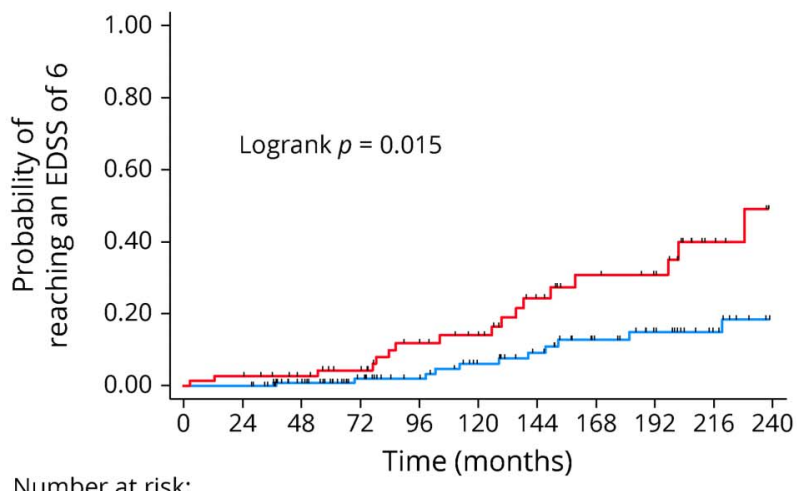

Number at risk:

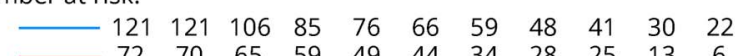

$E$

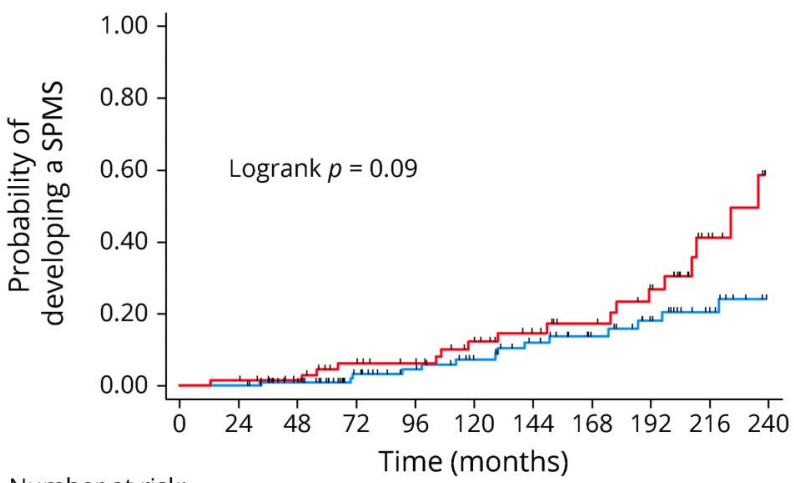

Number at risk:

$\begin{array}{ccccccccccc}121 & 121 & 106 & 84 & 75 & 66 & 58 & 49 & 41 & 29 & 21 \\ 72 & 71 & 66 & 58 & 53 & 46 & 39 & 34 & 28 & 14 & 6\end{array}$

$\mathrm{B}$

lgM index

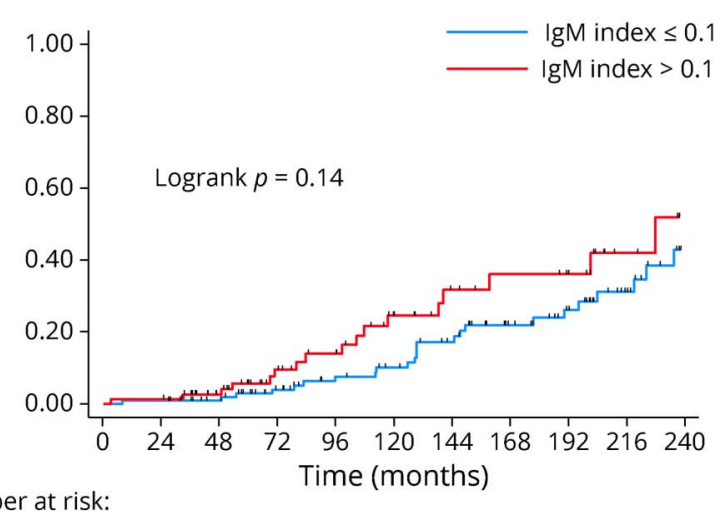

Number at risk:

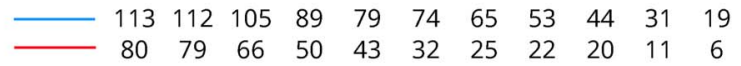

D

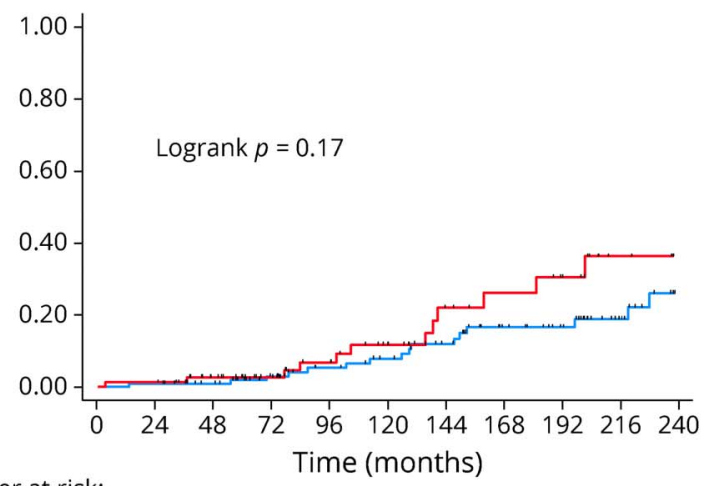

Number at risk:

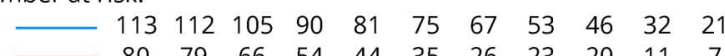

$\mathrm{F}$

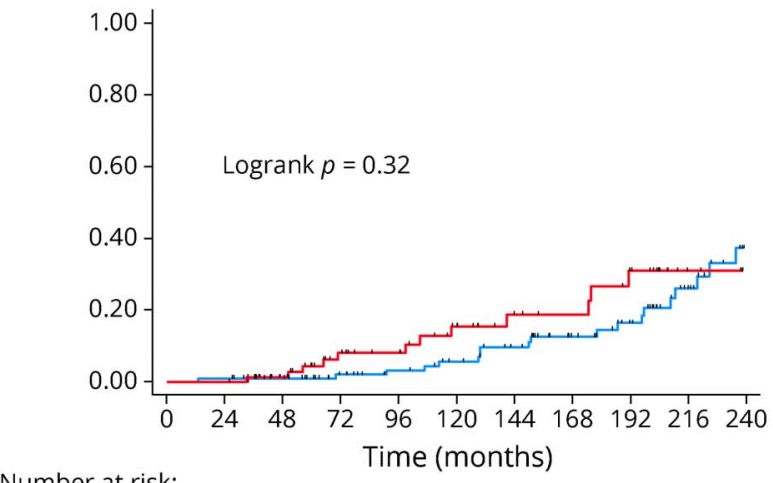

Number at risk:

$\begin{array}{ccccccccccc}113 & 112 & 105 & 91 & 83 & 77 & 69 & 57 & 48 & 32 & 20 \\ -80 & 80 & 67 & 51 & 45 & 35 & 28 & 26 & 21 & 11 & 7\end{array}$

Cumulative incidence with the log-rank test results for (A, B) EDSS score 4, (C, D) EDSS score 6, and (E, F) development of SPMS with (A, C, E) OCMB and (B, D, F) IgM index. EDSS = Expanded Disability Status Scale; Ig = immunoglobulin; OCMB = IgM oligoclonal band.

with a CIS for a median of 12.9 years. We compared the predictive value of 4 methods detecting ITMS in their ability at the disease onset to detect patients at risk of a poor disease evolution.
LS-OCMB significantly identified patients with a CIS with a higher risk of a second relapse, reaching EDSS scores of 4 and 6 and converting to SPMS at an earlier stage in both unadjusted and multivariate analyses. The risk was at least 
2-fold higher for all outcomes and was mainly evident for the risk of the EDSS score of 6, increased almost 5 times. This is especially relevant because despite $80 \%$ of patients with MS received at least $1 \mathrm{DMT}$ before reaching an EDSS score of 3 ( $16.4 \%$ also a highly effective DMT), the cumulative incidence of the EDSS score of 6 after 20 years reached almost 50\% among patients with LS-OCMB compared with less than $15 \%$ among patients without LSOCMB. On the other side, although the Reibergram and OCMB could also serve as valid tools, they only identified patients at risk of some of the end points and to a lesser degree. Conversely, IgM index showed a poor value in predicting all outcomes. All sensitivity analyses performed reinforced these findings.

Further analysis of the diagnostic accuracy of all methods showed that both LS-OCMB and Reibergram had a high specificity for predicting disability milestones, in contrast to OCMB and IgM index. However, LS-OCMB provided a 2fold significantly higher sensitivity than Reibergram, even if these results are probably underestimated by the effect of DMTs (especially for LS-OCMB), impossible to adjust in this case.

These results are consistent with the several previous studies that have associated ITMS (especially LS-OCMB) with a more aggressive course of MS in terms of disease activity and progression. ${ }^{10-28}$ However, it remained unknown whether the different methods provided similar accuracy. In this study, LS-OCMB showed a greater value than Reibergram, and this difference might probably be explained by the already reported lower sensitivity of Reibergram compared with OCMB. ${ }^{47,48}$ A positive Reibergram has strongly been associated with worse outcomes, ${ }^{21,26-28}$ but their higher percentage of falsenegative results compared with OCMB may diminish its utility. ${ }^{48}$ Compared with OCMB, LS-OCMB may identify more accurately those patients at a higher risk of early disability by the fact that OCMB might be due to transient immune activation while LS-OCMB a sustained IgM response associated with $\mathrm{CDS}^{+} \mathrm{B}$ cells. ${ }^{17}$ Regarding the IgM index, our negative results are in line with other studies ${ }^{18}$ related to the high number of $\mathrm{FP},{ }^{34}$ although conclusions cannot be accurately drawn as positive associations have been also described. ${ }^{24,28}$

For this reason, ITMS, when assessed by LS-OCMB, appears to be a good biomarker to identify patients who would be suitable to receive highly effective DMTs in an early stage.

Limitations were found in this study. The use of several DMTs on patients from this cohort could have affected the risk of subsequent disability, probably causing underestimation of the prognostic accuracy. This finding may be especially relevant for LS-OCMB as our group was using LS-OCMB as a biomarker of worse prognosis, and highly effective DMTs had been administered at earlier stages and more frequently (eTable 1, links.lww.com/NXI/A514) in these patients. However, the percentage of patients treated with highly effective DMTs before reaching the disability outcomes was less than $20 \%$, and Cox regression models were also adjusted by DMTs. Second, analyses were not adjusted by prognostic MRI markers such as T2 lesion load or $\mathrm{T} 1$ contrast-enhancing lesions, and thus, potential bias could have been introduced. Notwithstanding, future studies taking these variables into account are warranted. Third, the follow-up was variable across participants, and disability end points were generally achieved after a long period. However, a percentage of patients followed for $<5$ years were represented by only $16.1 \%$ of all the patients, and the sensitivity analysis restricted to patients with $>10$ years of follow-up yielded similar results.

Among patients with a typical CIS, the demonstration of ITMS by LS-OCMB accurately predicted a second relapse, the development of early disability, and conversion to SPMS. Thus, LS-OCMB, together with clinical and radiologic biomarkers, could help with the selection of patients at a higher risk of progression who would be potential candidates for receiving highly effective DMTs in an early stage.

\section{Acknowledgment}

The authors thank the labor of Asunción Fernández and Ana Isabel Pérez Macias as specialist nurses in multiple sclerosis for their assistance in the collection of samples and attention of patients.

\section{Study Funding}

This work was supported by grants FIS-PI18/00572 and RD16/0015/0001 from the Instituto de Salud Carlos III. Ministerio de Ciencia e Innovación. Spain and FEDER: "Una manera de hacer Europa."

\section{Disclosure}

E. Monreal received research grants, travel support, or honoraria for speaking engagements from Biogen, Merck, Novartis, Roche, Almirall, and Sanofi-Genzyme. S. Sainz de la Maza received payment for lecturing or travel expenses from Merck-Serono, Biogen, Sanofi-Genzyme, Roche, and Novartis. L. Costa-Frossard received speaker fees, travel support, and/or served on advisory boards by Biogen, Sanofi, Merck, Bayer, Novartis, Roche, Teva, Celgene, Ipsen, Biopas, and Almirall. P. Walo-Delgado, J. Zamora, J. I. Fernández-Velasco, N. Villarrubia, M. Espiño, D. Lourido, P. Lapuente, and I. Toboso report no disclosures relevant to the manuscript. J.C. Álvarez-Cermeño received compensations due to board membership or payment for lectures from Biogen, Merck-Serono, Bayer HealthCare, Novartis, Teva, Roche, and Sanofi. J. Masjuan reports no disclosures relevant to the manuscript. L.M. Villar received research grants, travel support, or honoraria for speaking engagements from Biogen, Merck, Novartis, Roche, SanofiGenzyme, Celgene, and Bristol-Myers. Go to Neurology. org/NN for full disclosures. 


\section{Publication History}

Received by Neurology: Neuroimmunology \& Neuroinflammation February 25, 2021. Accepted in final form June 14, 2021.

\section{Appendix Authors}

\begin{tabular}{lll}
\hline Name & Location & Contribution \\
\hline Enric & Hospital Universitario & Designed and conceptualized \\
Monreal, & Ramón y Cajal, Madrid, & $\begin{array}{l}\text { the study; major role in } \\
\text { MD }\end{array}$ \\
Spain & $\begin{array}{l}\text { acquisition of data; analyzed the } \\
\text { data; performed statistical } \\
\text { analysis; and drafted the } \\
\text { manuscript for intellectual } \\
\text { content }\end{array}$
\end{tabular}

\begin{tabular}{lll}
\hline $\begin{array}{l}\text { Susana } \\
\text { Sainz de la } \\
\text { Maza, MD }\end{array}$ & $\begin{array}{l}\text { Hospital Universitario } \\
\text { Ramón y Cajal, Madrid, } \\
\text { Spain }\end{array}$ & $\begin{array}{l}\text { Major role in acquisition of data } \\
\text { and revised the manuscript for } \\
\text { intellectual content }\end{array}$ \\
\hline $\begin{array}{l}\text { Lucienne } \\
\text { Costa- } \\
\text { Frossard, } \\
\text { MD }\end{array}$ & $\begin{array}{l}\text { Hospital Universitario } \\
\text { Ramón y Cajal, Madrid, } \\
\text { Spain }\end{array}$ & $\begin{array}{l}\text { Major role in acquisition of data } \\
\text { and revised the manuscript for } \\
\text { intellectual content }\end{array}$ \\
\hline $\begin{array}{l}\text { Paulette } \\
\text { Walo- } \\
\text { Delgado, } \\
\text { MD }\end{array}$ & $\begin{array}{l}\text { Hospital Universitario } \\
\text { Ramón y Cajal, Madrid, }\end{array}$ & $\begin{array}{l}\text { Major role in acquisition of data } \\
\text { and revised the manuscript for } \\
\text { intellectual content }\end{array}$ \\
\hline $\begin{array}{l}\text { Javier } \\
\text { Zamora, } \\
\text { PhD }\end{array}$ & $\begin{array}{l}\text { Hospital Universitario } \\
\text { Ramón y Cajal, Madrid, } \\
\text { Spain; Institute of }\end{array}$ & $\begin{array}{l}\text { Designed and conceptualized } \\
\text { the study; performed statistical } \\
\text { analysis; and revised the } \\
\text { manuscript for intellectual } \\
\text { Metabolism and System } \\
\text { Research. University of } \\
\text { content }\end{array}$ \\
& $\begin{array}{l}\text { Birmingham, UK } \\
\end{array}$
\end{tabular}

José Ignacio Hospital Universitario Major role in acquisition of data Fernández- Ramón y Cajal, Madrid, and revised the manuscript for Velasco, Spain intellectual content

MSc

\begin{tabular}{lll}
\hline Noelia & Hospital Universitario & Major role in acquisition of data \\
Villarrubia, & Ramón y Cajal, Madrid, \\
PhD & Spain & $\begin{array}{l}\text { and revised the manuscript for } \\
\text { intellectual content }\end{array}$
\end{tabular}

Mercedes Hospital Universitario Major role in acquisition of data Espiño, PhD Ramón y Cajal, Madrid, and revised the manuscript for Spain

\begin{tabular}{|c|c|c|}
\hline $\begin{array}{l}\text { Daniel } \\
\text { Lourido, MD }\end{array}$ & $\begin{array}{l}\text { Hospital Universitario } \\
\text { Ramón y Cajal, Madrid, } \\
\text { Spain }\end{array}$ & $\begin{array}{l}\text { Major role in acquisition of data } \\
\text { and revised the manuscript for } \\
\text { intellectual content }\end{array}$ \\
\hline $\begin{array}{l}\text { Paloma } \\
\text { Lapuente, } \\
\text { MD }\end{array}$ & $\begin{array}{l}\text { Hospital Universitario } \\
\text { Ramón y Cajal, Madrid, } \\
\text { Spain }\end{array}$ & $\begin{array}{l}\text { Major role in acquisition of data } \\
\text { and revised the manuscript for } \\
\text { intellectual content }\end{array}$ \\
\hline $\begin{array}{l}\text { Inmaculada } \\
\text { Toboso, PhD }\end{array}$ & $\begin{array}{l}\text { Hospital Universitario } \\
\text { Ramón y Cajal, Madrid, } \\
\text { Spain }\end{array}$ & $\begin{array}{l}\text { Major role in acquisition of data } \\
\text { and revised the manuscript for } \\
\text { intellectual content }\end{array}$ \\
\hline $\begin{array}{l}\text { José Carlos } \\
\text { Alvarez- } \\
\text { Cermeño, } \\
\text { PhD }\end{array}$ & $\begin{array}{l}\text { Hospital Universitario } \\
\text { Ramón y Cajal, Madrid, } \\
\text { Spain }\end{array}$ & $\begin{array}{l}\text { Designed and conceptualized the } \\
\text { study; major role in acquisition of } \\
\text { data; and revised the manuscript } \\
\text { for intellectual content }\end{array}$ \\
\hline $\begin{array}{l}\text { Jaime } \\
\text { Masjuan, } \\
\text { PhD }\end{array}$ & $\begin{array}{l}\text { Hospital Universitario } \\
\text { Ramón y Cajal, Madrid, } \\
\text { Spain }\end{array}$ & $\begin{array}{l}\text { Major role in acquisition of data } \\
\text { and revised the manuscript for } \\
\text { intellectual content }\end{array}$ \\
\hline $\begin{array}{l}\text { Luisa María } \\
\text { Villar, PhD }\end{array}$ & $\begin{array}{l}\text { Hospital Universitario } \\
\text { Ramón y Cajal, Madrid, } \\
\text { Spain }\end{array}$ & $\begin{array}{l}\text { Designed and conceptualized } \\
\text { the study; major role in } \\
\text { acquisition of data; analyzed the } \\
\text { data; drafted the manuscript for } \\
\text { intellectual content; and study } \\
\text { supervision }\end{array}$ \\
\hline
\end{tabular}

\section{References}

1. Lowenthal A, Vansande M, Karcher D. The differential diagnosis of neurological diseases by fractionating electrophoretically the CSF gamma-globulins. J Neurochem. 1960;6:51-56.

2. Tourtellotte WW, Potvin AR, Fleming JO, et al. Multiple sclerosis: measurement and validation of central nervous system IgG synthesis rate. Neurology. 1980;30(3): 240-244.

3. Felgenhauer $\mathrm{K}$, Reiber $\mathrm{H}$. The diagnostic significance of antibody specificity indices in multiple sclerosis and herpes virus induced diseases of the nervous system. Clin Investig. 1992;70(1):28-37.

4. Reiber H. Flow rate of cerebrospinal fluid (CSF): a concept common to norma blood-CSF barrier function and to dysfunction in neurological diseases. J Neurol Sci. 1994;122(2):189-203.

5. Andersson M, Alvarez-Cermeño J, Bernardi G, et al. Cerebrospinal fluid in the diagnosis of multiple sclerosis: a consensus report. J Neurol Neurosurg Psychiatry. 1994 57(8):897-902.

6. Thompson AJ, Banwell BL, Barkhof F, et al. Diagnosis of multiple sclerosis: 2017 revisions of the McDonald criteria. Lancet Neurol. 2018;17(2):162-173.

7. Sindic CJ, Monteyne P, Laterre EC. Occurrence of oligoclonal IgM bands in the cerebrospinal fluid of neurological patients: an immunoaffinity-mediated capillary blot study. J Neurol Sci. 1994;124(2):215-219.

8. Sharief MK, Thompson EJ. Intrathecal immunoglobulin $M$ synthesis in multiple sclerosis. Relationship with clinical and cerebrospinal fluid parameters. Brain. 1991 114(pt 1A):181-195

9. Fernández Ó. Is there a change of paradigm towards more effective treatment early in the course of apparent high-risk MS? Mult Scler Relat Disord. 2017;17:75-83.

10. Villar LM, Masjuan J, González-Porqué P, et al. Intrathecal IgM synthesis in neurologic diseases: relationship with disability in MS. Neurology. 2002;58(5):824-826.

11. Villar LM, Masjuan J, González-Porqué $\mathrm{P}$, et al. Intrathecal IgM synthesis predicts the onset of new relapses and a worse disease course in MS. Neurology. 2002;59(4): 555-559.

12. Villar LM, Masjuan J, González-Porqué $P$, et al. Intrathecal IgM synthesis is a prognostic factor in multiple sclerosis. Ann Neurol. 2003;53(2):222-226.

13. Villar LM, Sádaba MC, Roldán E, et al. Intrathecal synthesis of oligoclonal IgM against myelin lipids predicts an aggressive disease course in MS. J Clin Invest. 2005;115(1): 187-194.

14. Perini P, Ranzato F, Calabrese M, Battistin L, Gallo P. Intrathecal IgM production at clinical onset correlates with a more severe disease course in multiple sclerosis. J Neurol Neurosurg Psychiatry. 2006;77(8):953-955.

15. Jongen PJ, Lycklama a Nijeholt G, Lamers KJ, et al. Cerebrospinal fluid IgM index correlates with cranial MRI lesion load in patients with multiple sclerosis. Eur Neurol. 2007;58(2):90-95.

16. Thangarajh M, Gomez-Rial J, Hedström AK, et al. Lipid-specific immunoglobulin M in CSF predicts adverse long-term outcome in multiple sclerosis. Mult Scler. 2008 14(9):1208-1213.

17. Villar L, García-Barragán N, Espiño M, et al. Influence of oligoclonal IgM specificity in multiple sclerosis disease course. Mult Scler. 2008;14(2):183-187.

18. Mandrioli J, Sola P, Bedin R, Gambini M, Merelli E. A multifactorial prognostic index in multiple sclerosis. Cerebrospinal fluid IgM oligoclonal bands and clinical features to predict the evolution of the disease. J Neurol. 2008;255(7):1023-1031.

19. Sola P, Mandrioli J, Simone AM, et al. Primary progressive versus relapsing-onset multiple sclerosis: presence and prognostic value of cerebrospinal fluid oligoclonal IgM. Mult Scler. 2011;17(3):303-311.

20. Boscá I, Magraner MJ, Coret F, et al. The risk of relapse after a clinically isolated syndrome is related to the pattern of oligoclonal bands. J Neuroimmunol. 2010; 226(1-2):143-146

21. Durante L, Zaaraoui W, Rico A, et al. Intrathecal synthesis of IgM measured after a first demyelinating event suggestive of multiple sclerosis is associated with subsequent MRI brain lesion accrual. Mult Scler. 2012;18(5):587-591.

22. Magraner MJ, Bosca I, Simó-Castelló M, et al. Brain atrophy and lesion load are related to CSF lipid-specific IgM oligoclonal bands in clinically isolated syndromes. Neuroradiology. 2012;54(1):5-12.

23. Ferraro D, Simone AM, Bedin R, et al. Cerebrospinal fluid oligoclonal IgM bands predict early conversion to clinically definite multiple sclerosis in patients with clinically isolated syndrome. J Neuroimmunol. 2013;257(1-2):76-81.

24. Ozakbas S, Cinar BP, Özcelik P, Baser H, Kosehasanoğullari G. Intrathecal IgM index correlates with a severe disease course in multiple sclerosis: clinical and MRI results. Clin Neurol Neurosurg. 2017;160:27-29.

25. Tejeda-Velarde A, Costa-Frossard L, Sainz de la Maza S, et al. Clinical usefulness of prognostic biomarkers in optic neuritis [published correction appears in Eur J Neurol. 2018 Oct;25(10):1303]. Eur J Neurol. 2018;25(4):614-618.

26. Huss A, Abdelhak A, Halbgebauer S, et al. Intrathecal immunoglobulin M production: a promising high-risk marker in clinically isolated syndrome patients. Ann Neurol. 2018;83(5):1032-1036.

27. Pfuhl C, Grittner U, Gieß RM, et al. Intrathecal IgM production is a strong risk factor for early conversion to multiple sclerosis. Neurology. 2019;93(15):e1439-e1451.

28. Fonderico M, Biagioli T, Lanzilao L, et al. Prognostic role of intrathecal IgM synthesis in multiple sclerosis: results from a clinical series. Mult Scler. 2021;27(2):198-207.

29. Stauch C, Reiber H, Rauchenzauner M, et al. Intrathecal IgM synthesis in pediatric MS is not a negative prognostic marker of disease progression: quantitative versus qualitative IgM analysis. Mult Scler. 2011;17(3):327-334.

30. Frau J, Villar LM, Sardu C, et al. Intrathecal oligoclonal bands synthesis in multiple sclerosis: is it always a prognostic factor? J Neurol. 2018;265(2):424-430. 
31. Gasperi C, Salmen A, Antony G, et al. Association of intrathecal immunoglobulin G synthesis with disability worsening in multiple sclerosis. JAMA Neurol. 2019;76(7): 841-849.

32. Villar LM, González-Porqué P, Masjuán J, Alvarez-Cermeño JC, Bootello A, Keir G. A sensitive and reproducible method for the detection of oligoclonal IgM bands. J Immunol Methods. 2001;258(1-2):151-155.

33. Espiño M, Abraira V, Arroyo R, et al. Assessment of the reproducibility of oligoclonal IgM band detection for its application in daily clinical practice. Clin Chim Acta. 2015; 438:67-69.

34. Sharief MK, Keir G, Thompson EJ. Intrathecal synthesis of IgM in neurological diseases: a comparison between detection of oligoclonal bands and quantitative estimation. J Neurol Sci. 1990;96(2-3):131-142.

35. Villar LM, Alvarez-Cermeño JC. Comment on the article by Stauch et al. "Intrathecal IgM synthesis in paediatric MS is not a negative prognostic marker of disease progression: quantitative versus qualitative IgM analysis." Mult Scler. 2012;18(2): 250-253.

36. Reiber H, Rostasy K. Response to the letter of Villar et al. "Quantitative and qualitative IgM analysis in CSF.” Mult Scler. 2012;18(2):252-253.

37. Poser CM, Paty DW, Scheinberg L, et al. New diagnostic criteria for multiple sclerosis: guidelines for research protocols. Ann Neurol. 1983;13(3):227-231.

38. Lorscheider J, Buzzard K, Jokubaitis V, et al. Defining secondary progressive multiple sclerosis. Brain. 2016;139(pt 9):2395-2405.

39. Fogarty E, Schmitz S, Tubridy N, Walsh C, Barry M. Comparative efficacy of diseasemodifying therapies for patients with relapsing remitting multiple sclerosis: systematic review and network meta-analysis. Mult Scler Relat Disord. 2016;9:23-30.
40. Gasperini C, Prosperini L, Tintoré $\mathrm{M}$, et al. Unraveling treatment response in multiple sclerosis: a clinical and MRI challenge. Neurology. 2019;92(4):180-192.

41. Harding K, Williams O, Willis M, et al. Clinical outcomes of escalation vs early intensive disease-modifying therapy in patients with multiple sclerosis. JAMA Neurol. 2019;76(5):536-541.

42. Brown JWL, Coles A, Horakova D, et al. Association of initial disease-modifying therapy with later conversion to secondary progressive multiple sclerosis [published correction appears in JAMA. 2020 Apr 7;323(13):1318]. JAMA. 2019;321(2): 175-187.

43. Buron MD, Chalmer TA, Sellebjerg F, et al. Initial high-efficacy disease-modifying therapy in multiple sclerosis: a nationwide cohort study. Neurology. 2020;95(8): e1041-e1051.

44. He A, Merkel B, Brown JWL, et al. Timing of high-efficacy therapy for multiple sclerosis: a retrospective observational cohort study. Lancet Neurol. 2020;19(4):307-316.

45. Ontaneda D, Tallantyre E, Kalincik T, Planchon SM, Evangelou N. Early highly effective versus escalation treatment approaches in relapsing multiple sclerosis. Lancet Neurol. 2019;18(10):973-980.

46. Petzold A. Intrathecal oligoclonal IgG synthesis in multiple sclerosis. J Neuroimmunol. 2013;262(1-2):1-10.

47. Kaiser R, Lücking CH. Intrathecal synthesis of IgM and IgA in neurological diseases: comparison of two formulae with isoelectric focusing. Clin Chim Acta. 1993; 216(1-2):39-51.

48. Zeman D, Kušnierová $\mathrm{P}$, Všianský $\mathrm{F}$, et al. Cerebrospinal fluid oligoclonal IgM test in routine practice: comparison with quantitative assessment of intrathecal IgM synthesis. Clin Chim Acta. 2020;508:137-145. 


\section{Neurology \\ Neuroimmunology \& Neuroinflammation}

\section{Predicting Aggressive Multiple Sclerosis With Intrathecal IgM Synthesis Among Patients With a Clinically Isolated Syndrome \\ Enric Monreal, Susana Sainz de la Maza, Lucienne Costa-Frossard, et al. \\ Neurol Neuroimmunol Neuroinflamm 2021;8; \\ DOI 10.1212/NXI.0000000000001047}

This information is current as of July 22, 2021

\section{Updated Information \& Services}

References

Subspecialty Collections

Permissions \& Licensing

Reprints including high resolution figures, can be found at:

http://nn.neurology.org/content/8/5/e1047.full.html

This article cites 48 articles, 2 of which you can access for free at: http://nn.neurology.org/content/8/5/e1047.full.html\#\#ref-list-1

This article, along with others on similar topics, appears in the following collection(s):

Class II

http://nn.neurology.org//cgi/collection/class_ii

Multiple sclerosis

http://nn.neurology.org//cgi/collection/multiple_sclerosis

Prognosis

http://nn.neurology.org//cgi/collection/prognosis

Information about reproducing this article in parts (figures,tables) or in its entirety can be found online at:

http://nn.neurology.org/misc/about.xhtml\#permissions

Information about ordering reprints can be found online:

http://nn.neurology.org/misc/addir.xhtml\#reprintsus

Neurol Neuroimmunol Neuroinflamm is an official journal of the American Academy of Neurology.

Published since April 2014, it is an open-access, online-only, continuous publication journal. Copyright

Copyright $\odot 2021$ The Author(s). Published by Wolters Kluwer Health, Inc. on behalf of the American

Academy of Neurology.. All rights reserved. Online ISSN: 2332-7812.

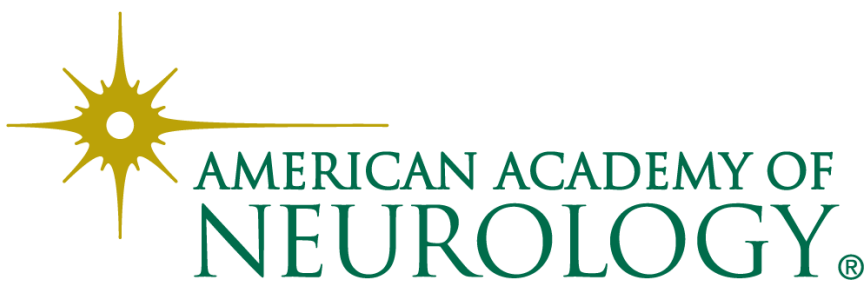

